\title{
Dental regulator pays damages after unlawful under-guise operation
}

The General Dental Council (GDC) has paid an undisclosed sum of damages to a clinical dental technician after Dental Protection successfully secured an admission by the regulator to having acted 'unlawfully in undertaking an under-guise operation without reasonable justification'.

Dental Protection defended their member, who had been the subject of an anonymous complaint to the GDC that he may be working without registration, and that his laboratory was in a bespoke setting in his home.

The GDC instructed an under-guise operation creating a fictitious scenario with two private investigators posing as relatives of 'Evelyn', an elderly relative who needed dentures but was too ill to attend in person.

The Interim Orders Committee concluded that any evidence from the investigation was flawed and unfair, and the GDC Fitness to Practise Committee halted any further action on grounds of an abuse of process. Most recently, the GDC accepted a declaration by the court that it has acted unlawfully by undertaking an under-guise operation without reasonable justification. This is in breach of the clinical dental technician's rights under Article 8 of the European Convention on Human Rights, the Data Protection Act 1998 and Data Protection Act 2018.
While the exact number of covert investigations undertaken by the GDC has not been established, a Freedom of Information request revealed that it spent a minimum of $£ 15,416$ on this in 2017 alone.

Raj Rattan, Dental Director at Dental Protection, said: 'The GDC targeting its own registrants without a sufficiently justified cause is extremely concerning for dentists. The use of an entirely contrived scenario about a sick pensioner in very difficult circumstances was designed to trigger an emotional response and lure a registrant into acting outside of their scope. This is hardly an ordinary opportunity for wrongdoing, and it is unfair and invasive.

'Throughout this case, the GDC asserted that under-guise investigations are essential to carry out its statutory function. However, in an unprecedented step, it has now admitted acting unlawfully when using under-guise investigations in this case and has agreed paying damages to our member.

'This has been a harrowing time for our member, and we hope that no one else needs to suffers in the same way.

'We have very strong concerns about the use of undercover investigators. Dental professionals should be able to be confident that any investigation into them is based on their real-life practice and interactions with others, and not on concocted situations with operatives actively seeking to gather evidence that could be used against them'

BDA Chair Eddie Crouch added: 'The use of Cloak and dagger tactics against innocent registrants underlines the need for fundamental change at the GDC.

'A devil may care attitude has left registrants footing the bill for unlawful activity, and the resulting legal costs.

'The GDC has tried justifying its approach. Clearly the courts have taken a different view and we now expect our regulator clarifies its future policy in this area publicly as matter of urgency.'

In response, General Dental Council Executive Director, Fitness to Practise, John Cullinane, said: 'The General Dental Council has used undercover investigators in fitness to practise cases extremely rarely. Where there is potential risk to the public, and where there is no other way to investigate a specific allegation that has been made, we will consider use of undercover approaches. A robust process is in place to assess risk to public health, safety and wellbeing, which is designed to balance public protection with the rights of the individuals concerned. We take this responsibility extremely seriously'.

\section{Dentists ready to work with next Scottish Government to rebuild services}

The British Dental Association has indicated it is ready to work with a future SNP government on wide-ranging pledges made in the party's manifesto, which could fundamentally change the way dentistry is delivered in Scotland.

The party has pledged to abolish patient charges over the course of the next parliament, and to work with the BDA to shape a reformed funding arrangement for NHS dentists so that they are supported for the future.

Approximately $20 \%$ of the NHS dental budget - some $£ 74$ million in $2018 / 19$ - is drawn from charges. The BDA believes charges represent a tangible barrier to care for those on modest incomes but will be seeking assurances that any move will not lead to a reduction in overall funding for the service.

The Scottish Budget 2021- 22 provided $£ 431$ million for general dental services, a rise of just $0.6 \%$ from the year before which represents a real-terms cut at a time the service faces an unprecedented backlog. The dental budget in Scotland has been cut in real terms in three out of the last four years.

The dentist's union has warned of widening inequality following the pandemic, with high street services operating at a fraction of their former capacity, with an estimated 2,500 children now facing up to year-long waits for dental extractions in hospitals.

Public Health Scotland data has shown a dramatic reduction in NHS dentistry due to COVID, which is hitting those in most deprived communities the hardest. Between April and November 2020, the number of courses of treatment delivered was $83 \%$ lower than during the same period in 2019. Practices are operating at significantly reduced capacity to meet infection control protocols, and the BDA is seeking capital investment in areas such as ventilation that can help restore patient volumes.

David McColl, chair of the British Dental Association's Scottish Dental Practice Committee, said: 'Dentistry in Scotland risks becoming a casualty of this pandemic. We have called for wholesale change to the way care is delivered, and we will work with the next Scottish Government to achieve that.

'These are big plans to bring down barriers to care and improve access, but they must go hand in hand with needed investment if services millions depend on are going to remain sustainable.

'Practices are now operating at a fraction of their former capacity. Dentists will need real and ongoing support if we're ever going to meet historic levels of demand.' 